\title{
Analysis of the Spatial Accessibility of Addis Ababa's Light Rail Transit: The Case of East-West Corridor
}

\author{
Andualem Aklilu ${ }^{1}$ Takele Necha ${ }^{1}$
}

Received: 13 June 2017/Revised: 30 October 2017/Accepted: 8 January 2018/Published online: 2 February 2018

(C) The Author(s) 2018. This article is an open access publication

\begin{abstract}
In this paper, spatial and statistical analysis methods were integrated to analyze the spatial accessibility, user population, and coverage of the Light Rail Transit of Addis Ababa. Stations were found to be the least accessible due to five types of land use and road network-related causes: government and social institutions with large area compounds, low road network density, open spaces devoid of road network, natural barriers such as water courses and large area public squares. The study explicitly revealed stations with overlaps in their service areas as well as stations having neighborhoods which are uncovered with the current service areas, i.e., $4.7 \mathrm{~km}^{2}$ and $19.9 \mathrm{~km}^{2}$ uncovered areas are found within walking distances of 1200-1500 m and 1500-2000 m, respectively; nonetheless, stations have fairly adequate coverage within $400 \mathrm{~m}$ and $800 \mathrm{~m}$ walking distance. Depending on the causes, stations were grouped into three categories. Service area-based determination of potential users is estimated to be 888,502 , while the total number of the daily average actual users is around 67,624. Generally an increase in the accessible population is associated with an increase in the service area coverage. However, the population accessibility and service area coverage do not directly imply more number of actual users. Stations with large overlap of service area have reduced number of actual users due to the fact that the accessible population is divided between shared stations. Therefore, unnecessary
\end{abstract}

Andualem Aklilu

anduak@yahoo.com

Takele Necha

takelenecha@yahoo.com

1 Ethiopian Civil Service University, Addis Ababa, Ethiopia

Communicated by Chun Zhang. large service area overlap is a wastage that does not contribute to more number of users. Future studies in the current study area might focus on considering the nexus between the accessibility and modal share as well as the long-term dynamics of the population of users.

Keywords Accessibility - LRT · Public transport · GIS · Network analysis - Land use - Walking distance

\section{Introduction}

\subsection{Background}

Aligned with the development of the geographical information system (GIS) and the expansion of its application in different disciplines, GIS application in transportation system, which is referred to as GIS-T, as stated in [1] has reached one of the most important application areas of GIS technology. In recent years, GIS has become an increasingly indispensible tool in the management and operationalization of the different transportation modes. In this respect, the use of spatial analysis in public transportation systems proven in many studies has enabled the systems to achieve their goals that include aspects such as sustainability, low cost, efficiency among others.

Accessibility in transportation domain is considered to be a broad and very flexible concept; as a result, it is occasionally confusing and complex. For simplicity, it could be described primarily from two viewpoints: that of the individual (origin) and that of the service provider (destination). [2] defined accessibility as "a way of measuring the ease with which a particular category of persons can reach a defined set of destinations, from a given origin (origin accessibility), or the ease with which a given destination 
(destination accessibility) can be reached by a particular set of potential individuals." Similarly [3] presented it as: "The ability of people being able to get to key services at reasonable cost, in reasonable time and with reasonable ease."

In transport and land use planning, accessibility is one of the key issues and walking is the most natural mode that is manifested [4]. The design of infrastructures such as public transport routes and stops, road network and the availability of various land use destinations (e.g., goods, services, employment, and social contacts) strongly influence accessibility. Accessibility is also used to address transportation issues such as equity and transport disadvantage [5]. Various approaches and methods have been developed to measure accessibility; [6] presented five major categories after reviewing various studies. Infrastructurebased measures that consider the performance of the network and entailing parameters such as capacity, frequency or reliability make the first group [7]. This method is also considered as a spatial separation model unveiled by [8], as it solely employs the physical distance between infrastructure elements as input, and it is convenient for the analysis of nodes and network structures. The method measures travel impediment or resistance between origin and destination between nodes and employed impediment measures viz., physical distance, network distance, travel time, travel cost, and service quality. It is facilitated to implement and demand minimal easy-to-obtain data input [9]. The second group is the cumulative measure that describes accessibility from a location (origin) to another (destination) and is the most easily understood measure and is often labeled as contour measure due to the involved contour maps which are produced in the process [10-12]. Gravity-based measure which is basically an extension of cumulative measures is the third category; it evaluates the opportunities by cost factor and the attractiveness of the destination. The method yields relative measure of accessibility between two points within a given area [13-16]. The other group called utilitybased measure considers travel behavior in terms of selecting the location based on economic principles of diminishing return [17, 18]. Activity-based measure is also placed separately, and it is associated with the level of access for individuals to spatially distributed activities, addresses location of activities, travels via the network and integrates a behavioral element [19-21].

Different transportation accessibility studies made use of the capability of GIS. Accordingly, [22] for instance applied GIS for analyzing railways origin-destination path selecting behavior. Via incorporating walking time, waiting time, riding time, transfer time and cost, GIS is used to analyze whether the destinations are found within walking distance of their origins. [23] applied GIS for accessibility analysis in metro and train lines. Likewise, [24] presented detailed and comprehensive approach that described and illustrated an integrated GIS tool called ACCESS for accessibility analysis. The framework includes in one platform GIS functionality, origin-destination matrix formulation and accessibility measures. Furthermore, [25] compared two location-based methods: Structural Accessibility Layer and the Public Transit and Walking Accessibility Index for measuring accessibility.

On the other hand, in public transport management, catchment area analysis of stops or stations are employed to evaluate the potential number of users. These methods have been used mainly in the planning stage as well as the management process and are composed of two types: the circular buffer approach and catchment area analysis. The circular buffer approach or Euclidean buffer is the most commonly used one, while the catchment area analysis considers the nature of road network and impedance or barriers which enables a detailed analysis and offers valid and effective results. Thus, [26, 27] asserted that GISbased catchment area analysis is preferred to simple circular buffer analysis that ignores physical barriers such as buildings, water bodies, freeways and that the former could support in decision-making tool in planning of mass transit lines, station positioning, and accessibility studies.

In this paper, the different major categories of accessibility measures, infrastructure or spatial-based measures are adopted and coupled with GIS. To this end, the catchment areas are considered as origin, while LRT stations are destination.

\subsection{Problem Statement}

The city of Addis Ababa developed and launched its first LRT system in September 20, 2015 as a response to the transportation problem which is one of the most important issues. The project is the first of its kind in sub-Saharan Africa, has a total length of $31 \mathrm{~km}$ and an expected train speed of $20-70 \mathrm{~km} / \mathrm{h}[1,28]$. It is stated with a capacity of 60,000-80,000 passengers per hour (PPH) in four directions [29].

Since its operationalization, the system has been praised as it helped a lot in the alleviation of the acute transportation problems in the two corridors (East-West and North-South); nevertheless, it is evident that customer dissatisfactions have been reported. On the other hand, it is possible to make an argument that the encountered problems are inevitable as the LRT system has only short life span and is the first of its type in the country; it is also obvious that the problems should be assessed and solutions should be considered promptly. In this regard, as observed by the researchers and reported by media outlets, the low statuses of service provision performance indicators have paramount importance.

Furthermore, from the academic point of view, the motivation of this research is to investigate the detailed 
relationship between the catchment area, overlap area, uncovered area and population users, which is not addressed in spatial platform in previous studies. This is also crucial from overall management perspective of the LRT since identification of the catchment areas for each station, quantification of the total population served by the system, and revealing the potential in neighborhood users yet the limited coverage due to poor accessibility to station among the untapped areas.

Therefore, addressing such issues is crucial for two reasons at least: first, it enables to improve the service provision performance of the system and to increase customer satisfaction; second, to obtain valuable references and practical guidelines from experience before the design and implementation of the second phase for the town.

\subsection{Objectives}

- To analyze the spatial accessibility of stations on the East-West corridor of LRT.

- To unveil the duplicate service area coverage of the East-West corridor of LRT.

- To reveal the potential accessible neighborhood yet uncovered service area by the East-West corridor of LRT system.

- To determine the total number of population who use the East-West corridor of the LRT.

\section{Research Methodology}

\subsection{General}

Both primary and secondary data were collected via various methods, such as direct field data collection sheet, hand-held geographical positioning system (GPS) data collection, digital spatial data sources, and document review. The research employed the softwares such as: ArcGIS 10.2 and Microsoft office packages; also, it exploited online spatial data source platforms including Google Earth and OpenStreetMap. Spatial network analysis, visual analysis and descriptive statistics methods were the major analyses used to produce the outputs: maps, tables, and graphs. The following section presents the details for each part in the methodology.

\subsection{Data Collection}

This study employed two major types of data which include spatial and non-spatial from both primary and secondary sources. Digital road network and land use data obtained from Addis Ababa city council as well as orthophoto of the city were the principal spatial data; furthermore, the satellite imagery of the study area was also used. Point latitude and longitude $(\mathrm{X}, \mathrm{Y})$ data showing the absolute locations of the twenty-two rail stations found in the East-West corridor of LRT were collected using hand-held GPS. The details of major road and LRT infrastructure in Addis Ababa are displayed in Fig. 1. In contrast, the non-spatial data embrace the average ticket sold, which is an estimate of user population, at each of the twenty-two stations of the East-West corridor was obtained from LRT head office of Addis Ababa. The population projection of Addis Ababa city for the year 2016 at suburban level by central statistics agency also served as crucial data in the study. Moreover, different forms of published and unpublished documents: academic, policy, reports, and manuals were exploited.

\subsection{Data Verification, Storage, and Maintenance}

The collected primary and secondary data were checked for consistency and missing values before using them for further analysis. Data collected using GPS were downloaded into ArcGIS and projected and stored in shapefile. All the spatial data: road, land use, LRT stations point data, and orthophoto of the study area were stored in

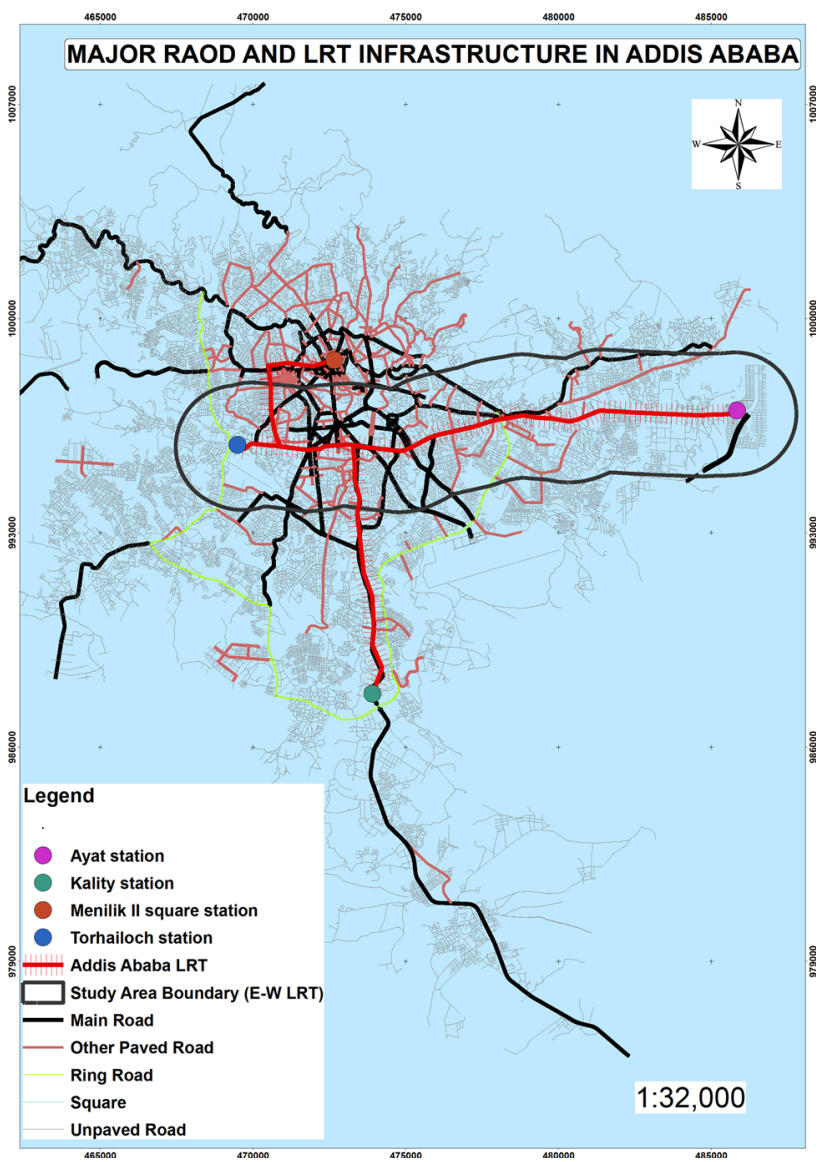

Fig. 1 Road and LRT Infrastructures in Addis Ababa 
geodatabase. Afterward, for road polyline shapefile missing attribute data were populated using data from primary and secondary sources.

In ArcMap and ArcCatalog applications of ArcGIS, the methods for road polyline shapefile is supported with the objective of correcting pertinent topological errors. First, topology was created using topology regulations including rules such as roads must not overlap, roads must not self-intersect, and roads should not have dangles. Second, the errors were verified and appropriate correction was implemented using topology editing tool, and ultimately error-free digital road shapefile obtained that could be used to create road network dataset.

Non-spatial data, notably ticket sold and population were stored in Microsoft Excel and Word so as to be used for further analysis.

\subsection{Data Analysis and Display}

Two major data analysis methods namely GIS Analysis and Descriptive Analysis were the major employed data analysis.

\subsubsection{Road Network Dataset Building and Service Area Coverage Analysis}

By using Network Analyst extension tool in ArcMap application of ArcGIS, new road network dataset was created from the error-free road shapefile. Subsequently, service area coverage polygons, which disclosed the accessible areas for each station, were generated in eight categories of walking distance impedances namely 300, $400,500,800,1000,1200,1500$, and $2000 \mathrm{~m}$. The adoption of the eight categories of walking distances is based on two major factors: experience from previous studies and average walking distance value of Addis Ababa city. Thus, previous studies unveiled different standards for measuring walking distance to rail stations or stops. The minimum measure is $300 \mathrm{~m}$ [30], while the maximum used is 1259 [27]; and 400 and $800 \mathrm{~m}$ are the most commonly used measures [31]. Accordingly, six classes of walking distances: 300, 400, 500, 800, 1000, and $1200 \mathrm{~m}$ were selected. However, the average walking distance in Addis Ababa city is equal to $1500 \mathrm{~m} \mathrm{[32].} \mathrm{And} \mathrm{as} \mathrm{walking} \mathrm{is} \mathrm{the}$ dominant mode of travel that took $60 \%$ of the urban trip, for complete understanding two categories of walking distances 1500 and $2000 \mathrm{~m}$ were also included which make a total of eight classes.

\subsubsection{Population Accessibility Analysis}

Through combining population data of the sub-cities for the year 2016 of the study area and respective area of the sub-cities, population density for each sub-city of the study area was computed using the following equation.

$\mathrm{PD}=P \div A$

where $P=$ Population of sub-city, $A=$ Area of sub-city, $\mathrm{PD}=$ Population density.

Afterward, the population within each service area coverage polygon was calculated. In this case, non-overlapping service areas were computed

$\mathrm{PA}=\mathrm{PD} * \mathrm{SA}$

where PA $=$ Population of service area, $\mathrm{PD}=$ Population density, $\mathrm{SA}=$ Area of service area coverage.

\subsubsection{Duplicate Service Area Coverage Analysis}

Areas found within the service area coverage and which are accessible to more than one station within walking distance are called duplicate coverage, and in this study duplicate coverage was determined as the intersection areas of service area coverage in two consecutive stations. In short, separate overlapping service area polygons were first generated and the overlap areas (duplicate) were then calculated using the spatial intersection tool of ArcMap.

$\mathrm{DA}=\left(\mathrm{SA}_{i} \cap \mathrm{SA}_{i+1}\right) U\left(\mathrm{SA}_{i} \cap \mathrm{SA}_{i-1}\right)$

where $\mathrm{DA}=$ Duplicate service area, $\cap=$ intersection, $\mathrm{SA}_{i}=$ Service Area of Station $i, \mathrm{SA}_{i+1}=$ Service Area of Station $i+1, \mathrm{SA}_{i-1}=$ Service Area of Station $i-1$.

\subsubsection{Uncovered Area (Gap) Analysis}

Uncovered areas are areas that are potentially accessible to stations but are not accessible currently due to several reasons. In this study, uncovered areas are those found within Euclidian distance but not within walking distance of a given category. Therefore, by using multiple buffer distances (Euclidian distance of 400 and $800 \mathrm{~m}$ ), service areas were determined first. Second, service areas were computed using 400- and 800-m walking distances. Finally, uncovered area was calculated as the difference between areas computed using buffer distances and walking distances for respective categories (400 and $800 \mathrm{~m}$ ).

$\mathrm{UA}=\mathrm{SAED}-\mathrm{SAWD}$

where UA $=$ uncovered area, $\mathrm{SAED}=$ service area based on Euclidian distance, SAWD = service area based on walking distance.

Two online spatial data source platforms: Google Earth and OpenStreetMap that provide detailed land use and place names among others were used to explain and analyze the causes of why stations have uncovered areas 
and also have small service area coverage, which relate to the nature of road and land use.

\subsubsection{Descriptive Analysis and Output Display}

Microsoft Excel was used to make simple arithmetic calculations as well as for computing averages, percentages, and totals. Correlation coefficients were calculated for some parameters, such as population, service area, and ticket sold in Microsoft Excel. Besides the analysis outputs: charts and tables were also prepared in Microsoft Excel, while maps were prepared in ArcMap. Finally, the full manuscript preparation was done using Microsoft word.

\section{Result and Discussion}

\subsection{Service Area Coverage}

\subsubsection{Service Area Coverage for 400- and 800-m Walking Distances}

As Table 1 reveals, based on 400-m walking distance Meri, Gurdshola 1, Hayahulet 2, Civil Service University,
Megenagna Adebabay, St Urael, Lem Hotel, and Hayhulet 1 stations have the largest service area coverage, while Torhailoch, Tegbared, Stadium, CMC, Management Institute, Bambis, Ayat and Gurdshola 1 stations have the smallest service area coverage. On the other hand, based on 800-m walking distance Megenagna, Gurd shola 1, Hayahulet 1, Civil Service University, St lideta, St Urael, Hayahulet 2, Lem Hotel, and Meri stations have the largest service area coverage; in contrast, Tegebared, Stadium, Torhailoch, Leghar, Management Instiute, CMC, Ayat, and Bambis Stations have the smallest area coverage among all stations.

Therefore, through the combined analysis of both the 400- and 800-m walking distances measures, Meri, Gurd shoal 1, Hayahulet 2, Civil Service University, Megenagna Adebabay, St Urael, Lem Hotel, and Hayahulet 1 stations are the most accessible stations in contrast to Torhailoch, Tegebared, Stadium, CMC, Management Institute, Bambis, and Ayat which are the least accessible among the total number of the twenty-two considered stations.

\subsubsection{Duplicate Coverage Area}

The spacing between stations is one of the parameters which influence the accessibility of stations; however, this
Table 1 Showing service area coverage of E-W stations for 400- and 800-m walking distances

\begin{tabular}{|c|c|c|c|c|c|}
\hline Facility ID & Station name & Area $\left(\mathrm{m}^{2}\right) / 0-400 \mathrm{~m}$ & $\%$ & Area $\left(\mathrm{m}^{2}\right) / 0-800 \mathrm{~m}$ & $\%$ \\
\hline 1 & Ayat & $110,641.6$ & 3.2 & $355,090.9$ & 3.1 \\
\hline 2 & Bambis & $90,466.5$ & 2.6 & $366,827.3$ & 3.2 \\
\hline 3 & Civil Service University & $237,385.8$ & 6.9 & $745,493.7$ & 6.5 \\
\hline 4 & $\mathrm{CMC}$ & $70,468.8$ & 2.0 & $345,186.3$ & 3.0 \\
\hline 5 & Coca Cola & $163,380.8$ & 4.7 & $491,765.3$ & 4.3 \\
\hline 6 & Gurd Shola 1 & $261,219.3$ & 7.6 & $840,403.7$ & 7.3 \\
\hline 7 & Gurd Shola 2 & $118,513.4$ & 3.4 & $537,098.8$ & 4.7 \\
\hline 8 & Hayahulet 1 & $209,248.6$ & 6.1 & $755,628.2$ & 6.6 \\
\hline 9 & Hayahulet 2 & $252,950.5$ & 7.3 & $662,041.9$ & 5.7 \\
\hline 10 & Leghar & $151,794.2$ & 4.4 & $341,050.6$ & 2.9 \\
\hline 11 & Lem Hotel & $225,947.9$ & 6.5 & $626,431.0$ & 5.4 \\
\hline 12 & Management Institute & $71,653.5$ & 2.0 & $343,153.6$ & 3.0 \\
\hline 13 & Megenagna Adebabay & $235,129.4$ & 6.8 & $902,397.9$ & 7.8 \\
\hline 14 & Meri & $269,317.9$ & 7.8 & $626,031.3$ & 5.4 \\
\hline 15 & Mexico & $139,224.5$ & 4.0 & $588,077.2$ & 5.1 \\
\hline 16 & St Lideta & $162,069.8$ & 4.7 & $718,752.4$ & 6.2 \\
\hline 17 & St Michael & $164,725.4$ & 4.8 & $583,496.5$ & 5.1 \\
\hline 18 & St Urael & $227,434.6$ & 6.6 & $672,326.3$ & 5.8 \\
\hline 19 & Stadium & $64,540.8$ & 1.8 & $192,135.6$ & 1.6 \\
\hline 20 & Stifanos & $129,602.9$ & 3.7 & $374,128.5$ & 3.2 \\
\hline 21 & Tegbared & $42,321.2$ & 1.2 & $91,241.1$ & 0.7 \\
\hline \multirow[t]{2}{*}{22} & Torhailoch & $29,874.5$ & 0.8 & $265,434.9$ & 2.3 \\
\hline & Total & $3,427,912.9$ & 99.9 & $11,424,194.2$ & 100.0 \\
\hline
\end{tabular}

Produced by the study 
is made based on the presumption that there is a lack of a standard for a feasible and competent spacing globally. In Australia, and in most parts of Europe, local-stop services generally stop every $400 \mathrm{~m}$ (1/4 mile, 1320 feet). Some North American agencies stop as frequently as every $100 \mathrm{~m}$ (about 330 feet).

The duplicate coverage area is the area that has more than one stop within a set standard of walking distance. In most situations, on flat terrain, users need to be able to walk to one stop, but not to two stops, so duplicate coverage is a waste.

The duplicate service area analysis output showed an overlap area (Table 2 below) between service area coverages of two subsequent stations using 800-m walking distance (WD). Thus, Hayahulet 2-Hayahulet 1, Hayahulet 1-Lem Hotel, and Leghar-Stadium, Lem Hotel-Megenagna Adebabay, Management Institute-Civil Service University, Bambis-St Urael, Civil Service University-St Michael, and Mexico-Leghar have the largest overlaps of all; conversely, Tegbared-Mexico, Meri-Ayat, and Gurd Shola 2-Gurd Shola 1, CMC-Meri, St Michael-CMC, Megenagna Adebabay-Gurd Shola 2, and Gurd Shola 1-Management Institute have the lowest overlap of service areas among all stations. On one hand, those stations with largest overlap areas of service area coverage imply that there is no need to establish new stations; on the other hand, new stations might be required to be established for those with the lowest service area overlaps.

To understand the nature of the relationship between the distance between stations and overlap of service area for 800-m walking distance for consecutive stations, the data were disclosed using scatter plot (see Fig. 2) and generally it showed the presence of a linear relationship, and hence the correlation coefficient was calculated to estimate the strength of the relationship.

The correlation coefficient between the distance from stations to stations and the overlap areas using 800-m walking distance is -0.45 , indicating the finding that as distance between stations increases, overlap between subsequent service areas decreases; or the shorter the distance between stations, the larger the overlap between service areas of stations.

\subsection{Uncovered Area Analysis}

Uncovered areas are areas which are found within Euclidian distance but not within walking distances. Uncovered areas are computed as the difference between the service areas computed using multiple buffer distances (Euclidian distances) and service areas calculated using walking distance of the eight respective classes.

Table 2 Distance between consecutive stations and overlap areas between respective service areas

\begin{tabular}{|c|c|c|c|}
\hline Name & Name & Distance $(\mathrm{m})$ & Overlap area $\left(\mathrm{m}^{2}\right)$ in $800 \mathrm{~m} \mathrm{WD}$ \\
\hline 1 & Stadium-Stifanos & 607.3 & $127,271.7$ \\
\hline 2 & Stifanos-Bambis & 590.2 & $158,279.2$ \\
\hline 3 & Tegbared-Mexico & 635.6 & 674.9 \\
\hline 4 & Mexico-Leghar & 663.4 & $199,882.8$ \\
\hline 5 & Leghar-Stadium & 412.1 & $325,362.7$ \\
\hline 6 & Hayahulet 2-Hayahulet 1 & 685.3 & $375,004.0$ \\
\hline 7 & Bambis-St Urael & 699.5 & $255,001.8$ \\
\hline 8 & Torhailoch-Coca Cola & 720.9 & $129,063.3$ \\
\hline 9 & Management Institute-Civil Service University & 724.5 & $299,717.5$ \\
\hline 10 & Coca Cola-St Lideta & 728.6 & $191,663.2$ \\
\hline 11 & St Lideta-Tegbared & 768.4 & $161,082.8$ \\
\hline 12 & Hayahulet 1-Lem Hotel & 782.6 & $352,725.3$ \\
\hline 13 & Lem Hotel-Megenagna Adebabay & 799.2 & $303,400.4$ \\
\hline 14 & Civil Service University-St Michael & 845.2 & $202,868.3$ \\
\hline 15 & St Michael-CMC & 849.1 & $54,315.8$ \\
\hline 16 & Megenagna Adebabay-Gurd Shola 2 & 856.3 & $79,893.4$ \\
\hline 17 & St Urael-Hayahulet 2 & 953.5 & $150,052.3$ \\
\hline 18 & Gurd Shola 1-Management Institute & 970.8 & $101,017.0$ \\
\hline 19 & Gurd Shola 2-Gurd Shola 1 & 1054.9 & $24,174.7$ \\
\hline 20 & CMC-Meri & 1092.2 & $33,825.7$ \\
\hline 21 & Meri-Ayat & 2362.9 & $20,159.7$ \\
\hline
\end{tabular}




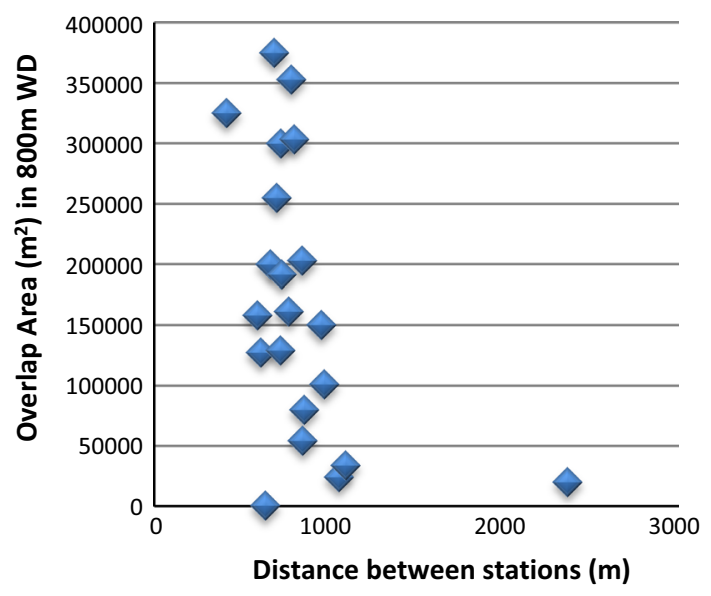

Fig. 2 Scatter plot of overlap area versus distance between stations

According to Table 3, among the total amount of uncovered area computed, uncovered areas that are found within walking distances of 1500-2000 m and $1200-1500 \mathrm{~m}$ are equal to $70 \%$ and $16 \%$, respectively. Conversely, very small percentages: $0.2 \%, 1.7 \%$ and $3.9 \%$ of overlap areas are found within walking distances of 0-400 m, 400-800 m, and 800-1000 m, respectively. Hence, it explicitly expounded the fact that there are very small proportions of the total area found within the 0-800$\mathrm{m}$ walking distance, which is the widely used measure applied in LRT planning and management.

\subsection{Population Accessibility}

\subsubsection{Population Density of Addis Ababa}

In order to calculate the total population who is accessible to the east-west LRT line based on the service area coverage which is described in the previous parts, population density is required. Accordingly, the projected population for each sub-city of Addis Ababa city for 2016 by central statistics agency and area of sub-cities are integrated to compute the population density (Peoples/Sq km) (Table 4).

The above-computed population densities for respective sub-cities are combined with service area coverage of

Table 3 Total uncovered service area gaps for six categories distance

\begin{tabular}{llcrr}
\hline No. & Distance $(\mathrm{m})$ & Total uncovered Area $\left(\mathrm{m}^{2}\right)$ & $\mathrm{km}^{2}$ & $\%$ \\
\hline 1 & $0-400$ & $68,407.0$ & 0.1 & 0.2 \\
2 & $400-800$ & $503,364.6$ & 0.5 & 1.7 \\
3 & $800-1000$ & $1,114,487.5$ & 1.1 & 3.9 \\
4 & $1000-1200$ & $1,758,131.8$ & 1.7 & 6.2 \\
5 & $1200-1500$ & $4,768,706.0$ & 4.7 & 16.9 \\
6 & $1500-2000$ & $19,916,478.2$ & 19.9 & 70.8 \\
& Total & $28,129,575.4$ & 28.1 & 100.0 \\
\hline
\end{tabular}

0-2000-m walking distance, and the total number of potential population who is accessible to the LRT system is computed.

\subsubsection{Estimated Potential Population Accessible to the LRT System within 0-2000-m Walking Distance}

Based on the 0.0-200-m walking distance service area coverage, the total number of population who is potentially accessible to the east-west LRT stations is estimated to be 888,502 . The most accessible among the 22 stations are Mexico, Coca Cola, Torhailoch and St Urael, whereas the least accessible includes Tegbared, Leghar, Management Institute and Meri. The total number of the daily average users (estimated based on ticket sold) is around 67,624 (Table 5). The busiest stations are Torhailoch, Ayat, Megenagna and Stadium compared to the relatively relaxed stations that include Management Institute, Civil Service University, Hayahulet 2 and St Urael. This indicated that although the potential user volume of the LRT is very large, the actual user volume is too small, and it is associated with the inefficiency or underperformance of the system, i.e., the low frequency of LRT that fails to provide adequate service with respect to the passenger volume. This is also proven by the congested user flow due to the over crowded situation of the system. Yet, 888,502 would decrease substantially if the study had considered and deducted the modal share of the different transportations in the area for the main modes such as private car and buses.

To identify the nature of the relationship between the ticket revenue sold per day and population that is accessible for $2000-\mathrm{m}$ walking distance, data were analyzed using scatter plot (see Fig. 3). The scatter plot showed that though it is dispersed, there exists a generally linear relationship, and hence correlation coefficient was performed to estimate the strength of the linear relationship.

The computed correlation coefficient between the population that is accessible and ticket revenue sold per day is equal to 0.14 showing a positive correlation. Moreover, the coefficient of determination $\left(r^{2}\right)$ equals to $0.02(2.07 \%)$ implying that only 2.07 percent variation of ticket sold per day is explained by the variation of the population that is accessible to the stations. This infers that the rise in the number of accessible population do not necessarily imply a greater number of actual users. This condition in turn could be associated with two main factors: first, even if people are accessible to the LRT, they could use other transportation alternatives, such as private cars and buses. Second, land use of the study area could also be influenced, i.e., for example, people who live within the commercial centers were likely to use the LRT more frequently compared to those who are in properties of other land uses. 
Table 4 Population projection values for the year 2016 and area of sub-cities and computed population density
Table 5 Total number of population accessible of LRT system within the 2000-m walking distance

\begin{tabular}{|c|c|c|c|c|c|c|}
\hline S. no. & Sub-city & Male & Female & Total & Area $\mathrm{km}^{2}$ & P.D (Peoples/Sq km) \\
\hline 1 & Akaki Kaliti & 107,852 & 113,907 & 221,759 & 123.4 & 1796.2 \\
\hline 2 & Nefas Silk-Lafto & 181,125 & 205,892 & 387,017 & 58.7 & 6586.4 \\
\hline 3 & Kolfe Keraniyo & 252,436 & 272,293 & 524,729 & 63.4 & 8266.0 \\
\hline 4 & Gulele & 157,311 & 170,115 & 327,426 & 31.1 & $10,497.7$ \\
\hline 5 & Lideta & 117,041 & 129,764 & 246,805 & 9.1 & $26,885.0$ \\
\hline 6 & Kirkos & 125,828 & 144,893 & 270,721 & 14.6 & $18,479.2$ \\
\hline 7 & Arada & 120,558 & 138,250 & 258,808 & 9.5 & $27,242.9$ \\
\hline 8 & Addis Ketema & 151,842 & 160,572 & 312,414 & 8.6 & $36,159.0$ \\
\hline 9 & Yeka & 196,452 & 227,765 & 424,217 & 82.1 & 5165.1 \\
\hline \multirow[t]{2}{*}{10} & Bole & 176,555 & 201,549 & 378,104 & 118.5 & 3190.7 \\
\hline & Total & $1,587,000$ & $1,765,000$ & $3,352,000$ & 519.4 & 6452.4 \\
\hline
\end{tabular}

\begin{tabular}{llcc}
\hline S.no. & Name & Population accessible & Ticket sold per day \\
\hline 1 & Tegbared & 7993 & 4701 \\
2 & Leghar & 9730 & 4323 \\
3 & Management Institute & 11,153 & 833 \\
4 & Meri & 11,543 & 2100 \\
5 & Gurd Shola 2 & 14,017 & 966 \\
6 & Lem Hotel & 16,510 & 1652 \\
7 & Hayahulet 1 & 19,625 & 1689 \\
8 & Civil Service University & 19,668 & 1000 \\
9 & Ayat & 20,312 & 6800 \\
10 & CMC & 21,734 & 2588 \\
11 & St Michael & 22,873 & 1466 \\
12 & Stadium & 23,549 & 5454 \\
13 & Megenagna Adebabay & 24,479 & 5766 \\
14 & Bambis & 36,938 & 1533 \\
15 & Gurd Shola 1 & 41,091 & 1966 \\
16 & Stifanos & 41,429 & 2733 \\
17 & Hayahulet 2 & 50,865 & 1666 \\
18 & St Lideta & 65,224 & 3073 \\
19 & St Urael & 67,552 & 1995 \\
20 & Torhailoch & 79,911 & 9533 \\
21 & Coca Cola & 108,479 & 2266 \\
22 & Mexico & 173,820 & 3512 \\
& Total & 888,502 &
\end{tabular}

Since the most commonly used measures of walking distance to stations are 400- and 8000-m walking distances, in Fig. 4 the population versus the two categories of walking distances are disclosed. Thus, Mexico, St Lideta, St Urael and Coca Cola stations are the most accessible ones whereas, CMC, Management institute, Ayat, and Gurdshola 2 are the least accessible stations.

\subsubsection{Detailed Analysis of Stations with Smaller Service Area Coverage}

In the previous part under section 3.1.1, Table 1 unveils the service area coverage for 400- and 800-m walking distances for each of the stations in the study.

In this part, the major underlying reasons for owning small area coverage for some of the stations that have less than $0.5 \mathrm{~km}^{2}$ area coverage are displayed based on the service area coverage analysis for $0-800 \mathrm{~m}$ walking distance. Generally, there are five major causes for having 


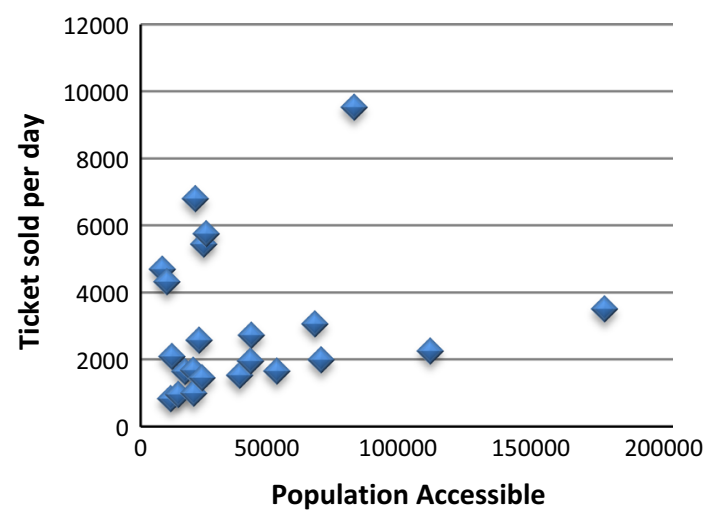

Fig. 3 Scatter plot of ticket sold per day versus population accessible

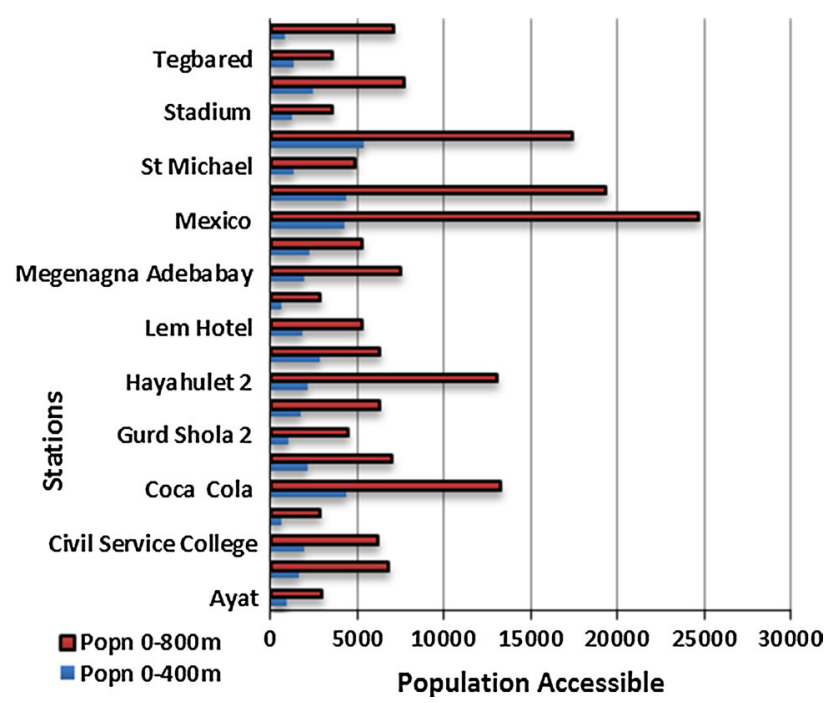

Fig. 4 Total number of population accessible within $0-400$ and 0-800 m distance

small service area coverage, namely government and social institutions with large area compounds, low road network density, open spaces devoid of road network, natural barriers such as water courses and large area public squares. Accordingly, taking these factors into account stations are grouped into three categories and presented here.

\section{A. Category One}

Stations under this category are characterized mainly by two major causes: low road network density and the presence of large compounds that impede the service areas. These include Tegebared, Stadium, Torhailoch, and Management Institute.

Tegebared, shown in Fig. 5a, has the lowest number of total population users among all stations, and this is attributed mainly to low road network density especially in the north direction of the station. Moreover, large compounds owned by government and business institutions, which separate the station from the surrounding neighborhood, are the second reason that contributed to the lowest number of users. For instance, A.A Tegebared industrial technology colleges, BGI Ethiopia, Ethiopian Federal police commission referral hospital are some of the institutions surrounding the station.

Stadium station has large uncovered service area in the south west direction due to the fact that large government and business owned compounds separate the area from the surrounding neighborhood (Fig. 5b).

In Torhailoch station, on the north and south direction of the station there are large compounds occupied by government institutions as well, such as Torhailoch hospital and social institutions like Addis Ababa Golf club (Fig. 5c).

With regard to the Management Institute, as shown in Fig. 5d, in the south eastern direction of the station, large area compound of St. Mariam church separated the station from the neighborhood. Likewise, in the northern direction, the compound of the Management Institute, another public institution, obsoletes the station from the surrounding neighborhood.

\section{B. Category Two}

This includes stations that own small service areas because of the open spaces that are undeveloped and large public squares, and the list under this category includes CMC, Legehar, Ayat and Stifanos. Considering CMC station (Fig. 6a), in the northern direction of the station, there is a large open space devoid of road network which is a major reason that created the smaller service area. Similarly in the southern direction, a big housing neighborhood with a large single compound called CMC is the major factor for smaller service area coverage.

The smaller service area coverage in Legehar (Fig. 6b) station is associated with large open space area owned by government institution, La Gare, devoid of road network, located in the southern and south-western direction from the station. Stifanos (Fig. 6c) is a large area of the uncovered areas for this particular station, it occurred due to two major reasons; first, the vast area occupied by Meskel square separated the neighborhood from the station; second, social service, for instance, Ghion hotel compound plays a similar role.

The open space, in the south eastern direction, of the Ayat station (Fig. 6d) is the vital cause for smaller service area.

\section{Category Three}

Here stations characterized by service areas impeded due to natural water barriers notably river courses are grouped and entail Coca Cola and Bambis. Coca Cola (Fig. 7a), in the southern direction of the station is faced with natural water course like the river which separated the uncovered area 

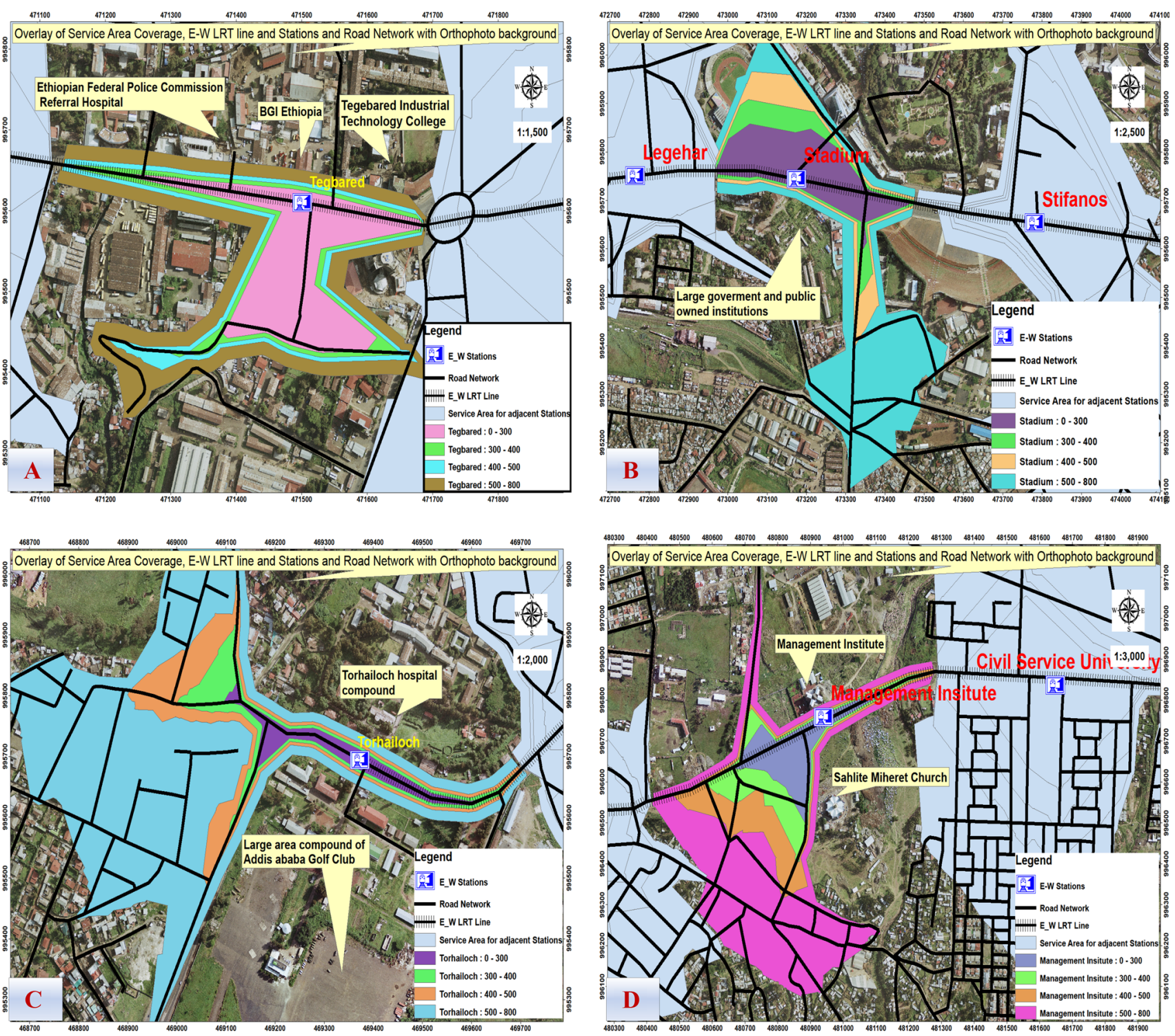

Fig. 5 Service areas of stations a Tegebared, b Stadium, c Torhailoch, d Management Institute

from station. In Bambis (Fig. 7b), there is low road network density both in the north and south direction from the station and specifically in the south direction of the station, there is a natural river water course that acts as a barrier to separate the neighborhood.

\subsection{Combined Analysis of Service Area Coverage, Overlap area, Uncovered Area, and Population Accessible, and Users Population}

In the previous sections, for 400- and 800-m walking distance, data on service area coverage, accessible population, duplicate service area coverage and revenue from sold tickets were presented. In the following sections, the type of relationship among the parameters was investigated.

\subsubsection{Analysis for 400-m Walking Distance}

To identify the degree and direction of relationship that could exist between each of the three parameters: service area, population accessible and ticket sold for 400-m walking distance, correlation analysis was performed, and the summary of the result is depicted in Table 6 .

Though a strong positive relationship was expected, the weak positive correlation coefficient (0.42) resulted between service area and population accessible suggests that service area is not the only parameter influencing the number of population accessible. For instance, population 

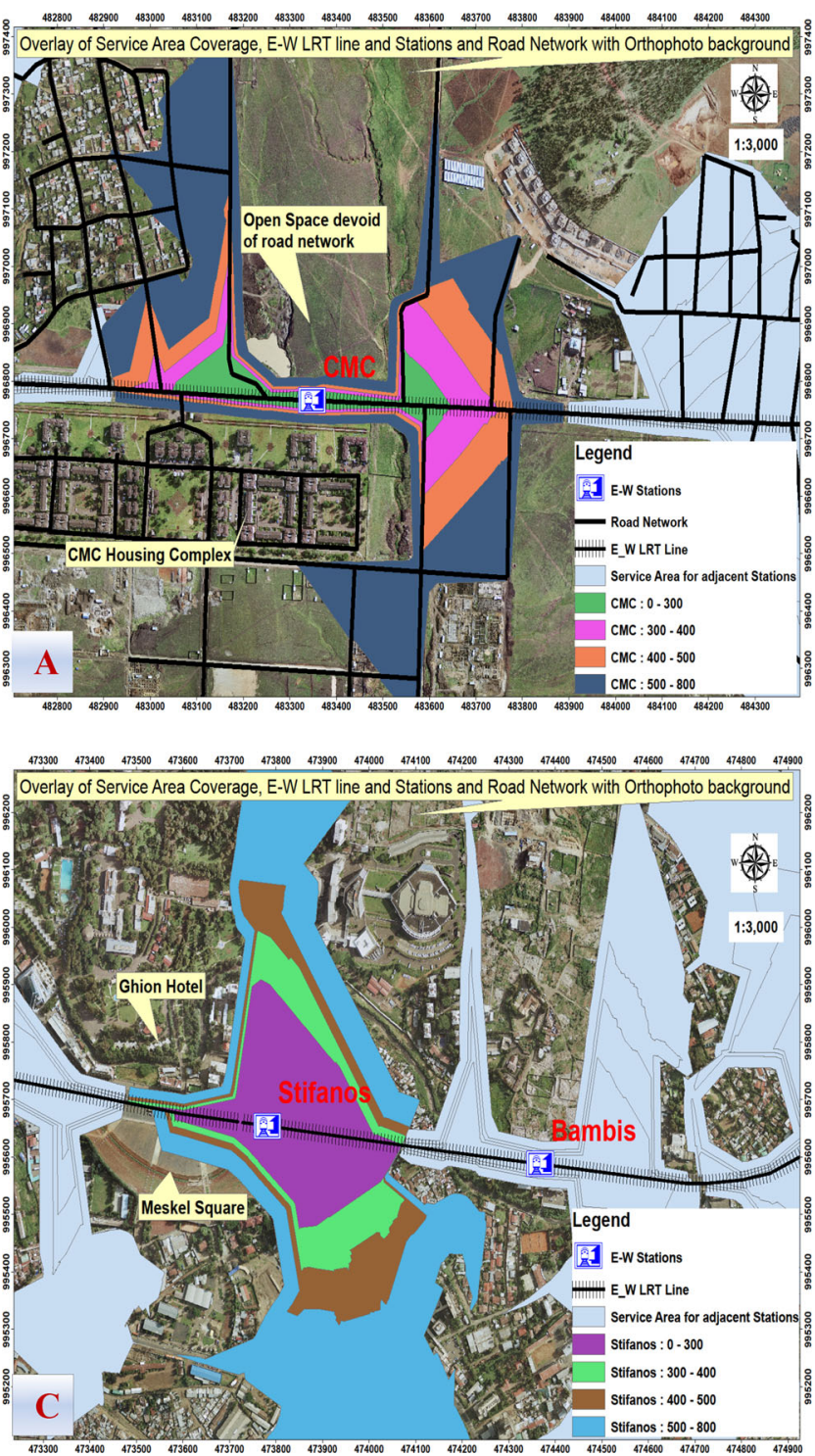

Fig. 6 Service areas of stations aCMC, b Legehar, c Stifanos, d Ayat

density could also be the other parameter that influences population accessibility as well.

Unlike the above, there exists a negative correlation coefficient $(-0.44)$ between service area coverage and ticket sold, which is also opposite to the hypothesis as service area increases, the number of ticket sold also increases. In addition, it revealed that within 400-m walking distance an increase in service area coverage does not imply an increase in the number of users. Similarly there exists a weak negative correlation between the accessible population and revenue from sold tickets $(-0.19)$. Therefore, within 400-m walking distance, the revenue from sold tickets is not influenced positively both by service area coverage and accessible population. This scenario suggests the possible influence of other parameters, for example, land use.
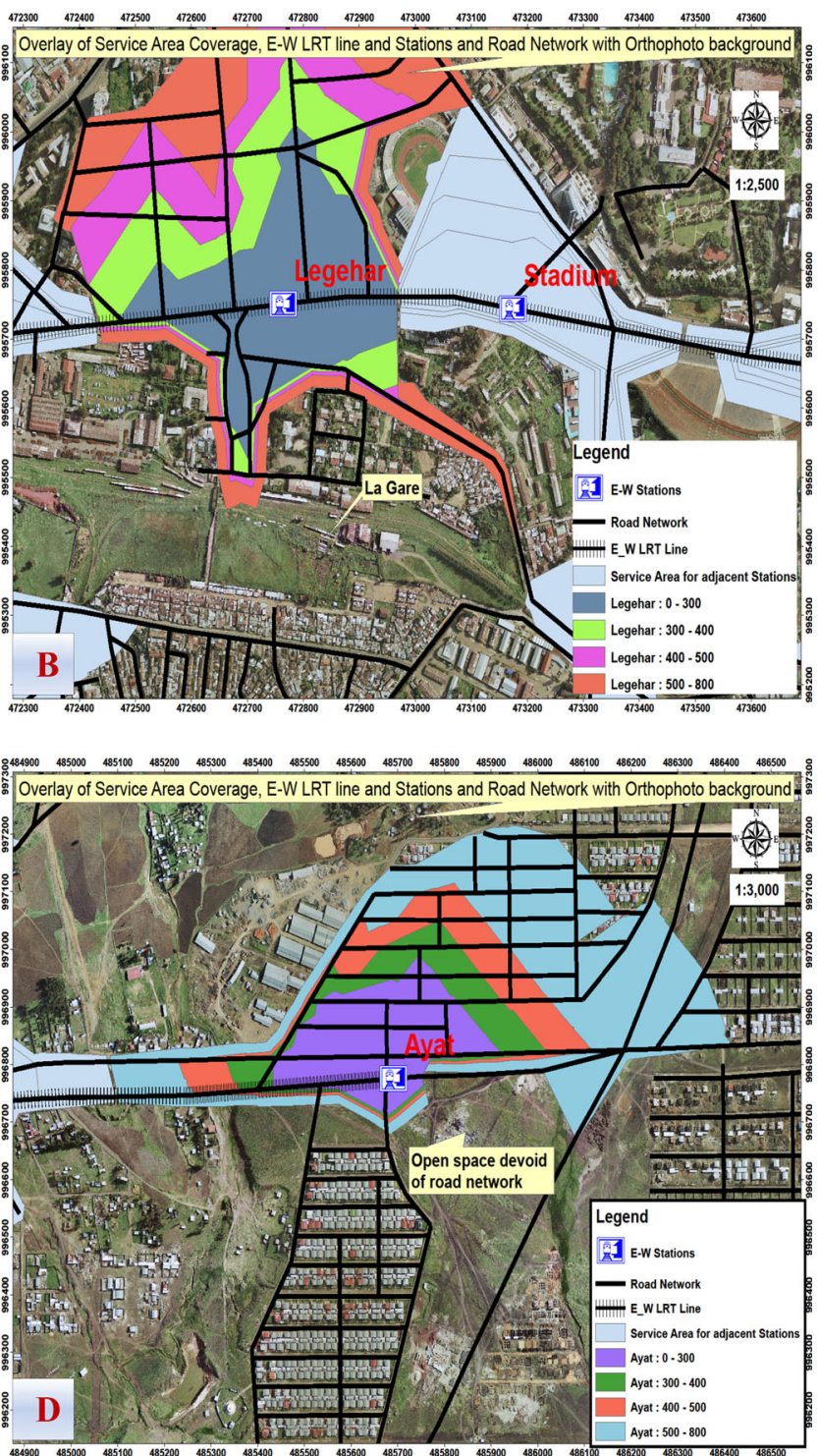

\subsubsection{Analysis for 800-m Walking Distance}

Likewise in the previous part, the possible correlations are examined for $800-\mathrm{m}$ walking distance and presented under Table 7.

Positive correlation coefficients are produced between each of the area and population, area and overlap, as well as the overlap and revenue from sold tickets.

Similar to the 400-m walking distance result discussed under 3.4.1 above, the coefficient of the correlation between service area coverage and accessible population $(0.37)$ is positive, and service area coverage and revenue from sold tickets $(-0.40)$ as well as the accessible population and revenue from sold tickets $(-0.07)$ are negative. This again revealed service area coverage and population accessible are not the parameters which positively 

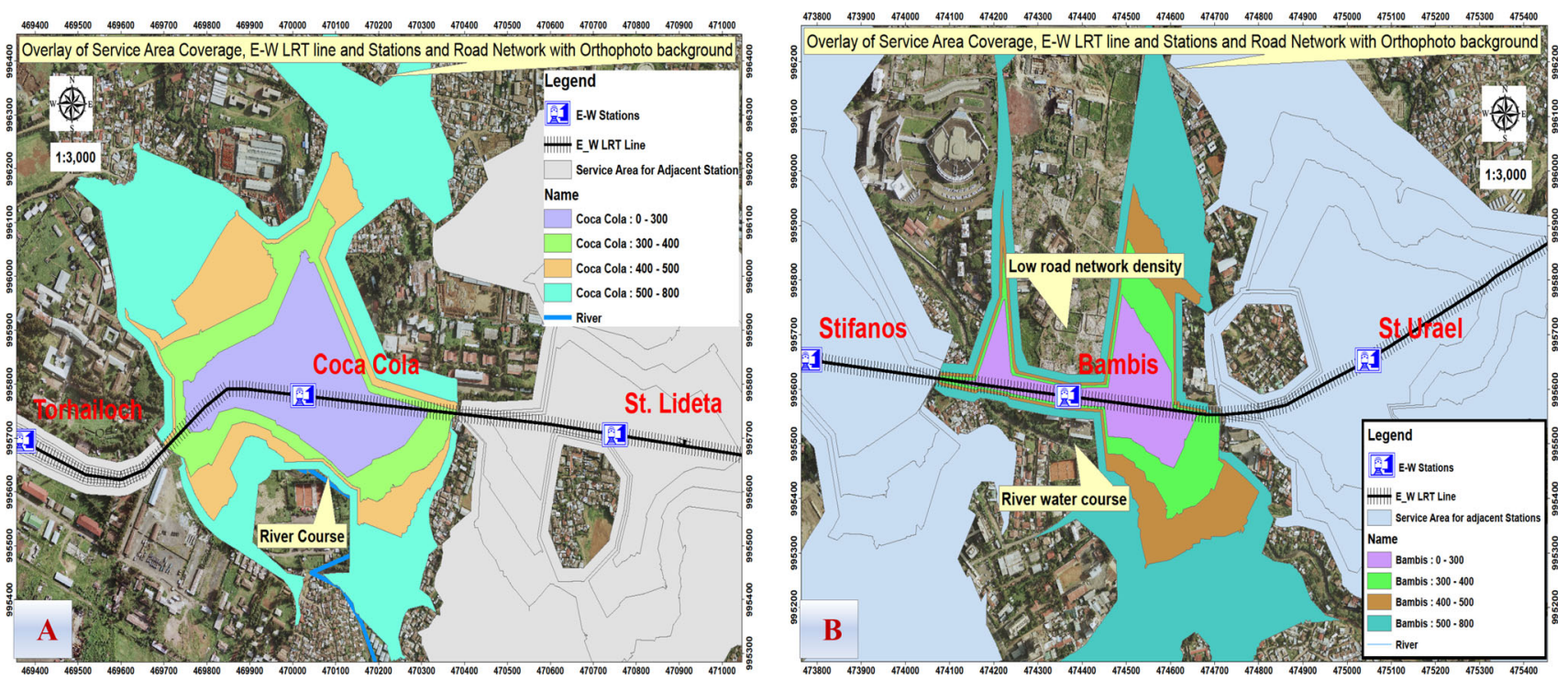

Fig. 7 Service areas of stations a Coca Cola, b Bambis

Table 6 Showing correlation coefficients (r) and coefficient of determination $\left(r^{2}\right)$ for 400 -m walking distance

\begin{tabular}{lrllll}
\hline Parameters & \multicolumn{2}{l}{ Service Area } & & \multicolumn{2}{l}{ Population Accessible } \\
\cline { 2 - 3 } \cline { 5 - 6 } & \multicolumn{1}{c}{$r$} & $r^{2}$ & & \multicolumn{1}{r}{$r^{2}$} \\
\hline Service area & 1.00 & - & - & - \\
Population accessible & 0.42 & $17.92 \%$ & & 1.00 & - \\
Ticket sold & -0.44 & $20.21 \%$ & -0.19 & $3.75 \%$ \\
\hline
\end{tabular}

nevertheless, users commonly use a single station and do not alternatively use or switch between stations. When the distance between stations is similar, other walking parameters such as congestion and road quality are used to choose the best station.

Conversely, the area and ticket revenue are negatively correlated implying that large areas do not produce more number of users.

\section{Conclusions and Recommendations}

influence ticket sold, and this implies the consideration of other parameters.

There exists a negative correlation coefficient between service area overlap and ticket sold $(-0.31)$. This scenario indicates the fact that within the 800-m walking distance as subsequent stations have large overlaps of their service area, then the ticket sold will be reduced as the users are divided between the stations. In other words, unnecessary large overlap of service area is a wastage that does not result in an increase in the total number of users in a station. Still it could be argued that more number of accessible stations is preferable from the users' perspective;

With the purpose of evaluating public transport accessibility, this study successfully applied both statistical and spatial analyses to examine the relationship between each of the service areas, population user, overlap areas, and uncovered neighborhood.

In terms of spatial accessibility, most stations are well accessed, while five major underlying causes were the impedances resulting in poor accessibility. Similarly, some stations were found to have large areas of overlaps, while some others with small overlap areas.

Only small proportion area is found to be uncovered using the $400-\mathrm{m}$ and $800-\mathrm{m}$ walking distance, while the

Table 7 Showing matrix of correlation coefficients for 800-m Walking distance

\begin{tabular}{lclll}
\hline & Service area coverage & Population accessible & Service area overlap & Ticket sold \\
\hline Service area coverage & 1.00 & - & - & - \\
Population accessible & 0.37 & 1.00 & - & - \\
Service area overlap & 0.26 & 0.09 & 1.00 & - \\
Ticket sold & -0.40 & -0.07 & -0.31 & 1.00 \\
\hline
\end{tabular}


lion share of the uncovered area: $70 \%\left(19.9 \mathrm{~km}^{2}\right)$ and $16 \%$ $\left(4.7 \mathrm{~km}^{2}\right)$ is found within walking distances of $1500-2000$ and $1200-1500 \mathrm{~m}$, respectively.

Based on the correlation analysis, generally an increase in population accessible is associated with an increase in service area coverage. Nevertheless, population accessibility and service area coverage do not directly imply more number of actual users. Other parameters such as the number of private and public car users and the type of land use are possibly the reasons behind the actual number of users.

Stations with large overlap of service areas have reduced number of actual users due to the fact that the accessible population are divided between the shared stations. Therefore, unnecessary large service area overlap is a wastage that does not contribute to more number of users.

Depending on the above conclusion, the following recommendations are promoted:

- For stations with small amount of service area coverage, an improvement in the density of road network is considered as one of the solutions.

- Future research on accessibility in the similar field of study should consider the modal share, i.e., the number of private car and buses usage, more detailed analysis of the influence of land use, and detailed data on population density.

Acknowledgement Upon the completion of this research, we would like to extend our appreciation to the Ethiopian Civil Service University and in particular to the Research and Publication Coordination Office [RPCO] not only for granting the budget for the accomplishment of the research but also for positive follow-up in the course of the research period. For discharging support as well as facilitation of the research routine activities, we are indebted to Dr Teshome Tafesse and Ato Zigiju. We are also thankful to the Addis Ababa LRT project office for offering data.

Open Access This article is distributed under the terms of the Creative Commons Attribution 4.0 International License (http://crea tivecommons.org/licenses/by/4.0/), which permits unrestricted use, distribution, and reproduction in any medium, provided you give appropriate credit to the original author(s) and the source, provide a link to the Creative Commons license, and indicate if changes were made.

\section{References}

1. Maguire DJ, Smith R, Jones S (1993) GIS on the move: some transportation applications of GIS. Proc Thirteen Annu ESRI User Conf 3:39-46

2. Simmonds DC, Still BG (1998) DELTA/START: adding landuse analysis to integrated transport models. In: Presented to the world conference on transport research, antwerp. proceedings of the world conference on transport research, vol 4
3. Social Exclusion Unit (2003) Making the connections: final report on transport and social exclusion, Office of the Deputy Prime Minister

4. Wibowo SS, Olszewski P (2005) Modeling walking accessibility to public transport terminals: case study of Singapore mass raid transit. J East Asia Soc Trans Stud 6:147-156

5. Yigitcanlar T, Sipe Nell, Evans Rick, Pitot Matt (2007) A GISbased land use and public transport accessibility indexing model. Aust Plan 44(3):30-37. https://doi.org/10.1080/07293682.2007. 9982586

6. Curl A, Nelson JD, Anable J (2011) Does accessibility planning address what matters? A review of current practice and practitioner perspectives. Res Trans Bus Manag 2:3

7. Church A, Frost M, Sullivan K (2000) Transport and social exclusion in London. Trans Policy 7(3):195-205

8. Bhat C, Handy S, Kockelman K, Mahmassani H, Chen Q, Weston L (2000) Development of an urban accessibility index: literature review. Research project conducted for the Texas Department of Transportation. Center for Transportation Research, University of Texas, Austin (TX), USA

9. Baradaran S, Ramjerdi F (2001) Performance of accessibility measures in Europe. J Trans Stat 4(23)

10. Nettleton M, Pass DJ, Walters GW, White RC (2007) Public transport accessibility map of access to general practitioners surgeries in Longbridge, Birmingham, UK. J Maps 2007:64-75

11. Casas I (2007) Social exclusion and the disabled: an accessibility approach. Prof Geogr 59(4):463-477

12. Escalona-Orcao A, Díez-Cornago C (2007) Accessibility to basic services in one of the most sparsely populated areas in Europe: the province of Teruel (Spain). Area 39(3):295-309

13. Bertolini L, le Clercq F, Kapoen L (2005) Sustainable accessibility: a conceptual framework to integrate transport and land use plan-making. Two test-applications in the Netherlands and a reflection on the way forward. Trans Policy 12(3):207-220

14. Geertman SCM, Van Eck JRR (1995) GIS and models of accessibility potential: an application in planning. Int J Geogr Inf Sci 9(1):67-80

15. Knox PL (1981) Retail geography and social well-being: a note on the changing distribution of pharmacies in Scotland. Geoforum 12(3):255-264

16. Hansen WG (1959) How accessibility shapes land use. J Am Plan Assoc 25(2):73-76

17. Bohnet M, Gertz C (2008) Mode specific accessibility and car ownership, mobil.TUM 2008 In: International conference on mobility and transport. (http://www.vsl.tuharburg.de/Archiv/Boh net_mobilTUM2008_Paper_Final.pdf)

18. Niemeier DA (1997) Accessibility: an evaluation using consumer welfare. Transportation 24(4):377-396

19. Buliung RN, Kanaroglou PS (2006) A GIS toolkit for exploring geographies of household activity/travel behavior. J Trans Geogr 14(1):35-51

20. Casas I (2007) Social exclusion and the disabled: an accessibility approach. Prof Geogr 59(4):463-477

21. Farber S, Páez A (2009) My car, my friends, and me: a preliminary analysis of automobility and social activity participation. J Trans Geogr 17(3):216-225

22. Yang Z, Hayashi Y (2002) GIS-based analysis of railway's origin/destination path-selecting behavior 2002. Computer-Aided Civil and Infrastructure Engineering by Blackwell Publishing, 350 Main Street, Malden, MA 02148, USA, and 108 Cowley Road, Oxford OX4 1JF, UK

23. Kesik OA, Aydinoglu AC, Sağlam D (2015) GIS based accessibility assessment for public services: istanbul case. FIG working week 2015 from the Wisdom of the Ages to the Challenges of the Modern World Sofia, Bulgaria, 17-21 May 2015 
24. Liu S, Zhu X (2004) An integrated GIS approach to accessibility analysis. Transactions in GIS, 2004, 8(1): 45-62. Blackwell Publishing Ltd. 2004. 9600 Garsington Road,Oxford OX4 2DQ, UK and 350 Main Street, Malden, MA 02148, USA

25. Albacete X, Olaru D, Paül V, Biermann S (2017) Measuring the accessibility of public transport: a critical comparison between methods in Helsinki. Appl Spat Anal 10:161-188. https://doi.org/ 10.1007/s12061-015-91778

26. Andersen JLE, Landex A (2009) GIS-based approaches to catchment area analyses of mass transit. In: ESRI international user conference

27. El-Geneidy A, Grimsrud M, Wasfi R, Tétreault P, SurprenantLegault J (2014) New evidence on walking distances to transit stops: identifying redundancies and gaps using variable service areas. Transportation 41(1):193-210
28. All Africa (2015) Ethiopia: addis light rail eases transportation problem. Retrieved 23 September 2015

29. Addis Ababa Online (2012) Addis Ababa light rail transit project reaches implementation. Availableathttp://addisababaonline.com/ addis-ababa light-rail-transit-project-reaches implementation

30. Alshalalfah B, Shalaby A (2007) Case study: relationship of walk access distance to transit with service, travel, and personal characteristics. J Urban Plan Dev 133:114-118

31. Gutierrez J, Garcia-Palomares JC (2008) Distance-measure impacts on the calculation of transport services areas using GIS. Environ Plan B Plan Des 35:480-503

32. UITP and UATP (2010) Report on statistical indicators of public transport performance in Africa. Version 1.3-Final version. Trans Africa 